\title{
Griginal The profile of inflammatory bowel disease in natives of Western Himalayas
}

\author{
Jai Bharat Sharma ${ }^{1}$, Brij Sharma², Rajesh Sharma², \\ Sanjay K Mahajan ${ }^{1}$, Rajiv Raina ${ }^{1}$, Priyanka Sharma ${ }^{3}$
}

\begin{abstract}
Correspondence: Jai Bharat Sharma
Email:jai561989igmc@gmail.com

${ }^{1}$ Department of Medicine, ${ }^{2}$ Department of Gastroenterology, ${ }^{3}$ Department of $O B G$ and Gynaecology. Indira Gandhi Medical College, Shimla, Himachal Pradesh.
\end{abstract}

Email. jais6reseigmeagmail.com

\section{ABSTRACT}

Background: To study the profile of Inflammatory Bowel Disease (IBD) in natives of Himachal Pradesh.

Material and Methods: A total of 101 patients of IBD were included. The clinical profiles, disease activity, severity and response to therapy were evaluated.

Results: Of the 101 patients, $82 \%$ were diagnosed with Ulcerative Colitis (UC), 12\% with Crohn's Disease (CD) and 6\% with Inflammatory Bowel Disease Unclassified (IBDU). The mean duration between onset of symptoms and diagnosis was 12.3 months for UC, 15 months for CD and 3 months for IBDU. Chronic diarrhea (98\%) and blood in stools (94\%) were most common symptom in UC and abdominal pain (83\%) was most common in CD. E2(45.78\%) disease was most common in UC, L2(50\%) was most common in $\mathrm{CD}$ and Left sided colonic involvement was most common in IBDU (83\%). Extra intestinal manifestations were noted in IBDU (67\%), CD (50\%) and UC (40\%). Most of the patients had moderate disease activity and responded well to pharmacotherapy.

Conclusion: IBD is not uncommon in the rural hilly areas of India. There is predominance of ulcerative colitis rather than Crohn's disease.

KEYWORDS: Inflammatory bowel disease; Himalayas; colitis; diarrhea.

\section{Introduction}

The idiopathic Inflammatory Bowel Diseases (IBD) comprise three types of chronic intestinal disorders: Crohn's Disease (CD) Ulcerative Colitis (UC) and Inflammatory Bowel Disease Undifferentiated (IBDU)/ Indeterminate Colitis. ${ }^{1}$ The incidence and prevalence rates of IBD in Asian countries are still low compared with those of Western countries, but have been increasing rapidly during the past decades. ${ }^{2}$ The incidence of IBD has dramatically increased during the 20th century, and in the developed nations is as high as 20 and 24 cases per 100,000 person-years for CD and UC, respectively. ${ }^{3}$ There are substantial variances in the incidence and 
prevalence rates of IBD among different races or ethnic groups in Asia, with the highest rates in India, Japan, and some Arab world. In England studies have indicated that the incidence of UC among migrant South Asians is higher than that of Europeans, suggesting that South Asians are genetically predisposed to UC. ${ }^{2}$ As developing countries, such as India and China, became industrialized, the incidence of IBD has risen in paralle. ${ }^{1}$ In developing countries in which IBD is emerging; UC is typically more common than $\mathrm{CD}$. In India, for example, there are reports of $\mathrm{UC} / \mathrm{CD}$ ratio of $8: 1 .^{4}$

Himachal Pradesh is located between 30'22' and 30 "'12' north latitude and between 75" 47 ' and 79"4' east longitude. It is a mountainous state in northern India, situated in western part of outer Himalaya in with altitudes ranging from 350 to 7000 meters above MSL. It is one of the least urbanized states in India, with predominantly agricultural economy. The life style and dietary habits of population in the area differs from those living in plains. The studies on IBD from this region not available thus this study was planned to know the profile of IBD from natives of this region.

\section{Methods}

The present study was conducted in Departments of Medicine and Department of Gastroenterology, Indira Gandhi Medical College, Shimla from 1st June 2014 to 31st May 2015. All consecutive patients of IBD above 18 years and who were natives of Himachal Pradesh were enrolled for the study. There were total of 101 patients enrolled, of these 43 were newly diagnosed (33 patients of UC, 8 patients of CD and 2 patients IBDU) and 58 old diagnosed patients on follow up (50 of UC and 4 each of $\mathrm{CD}$ and IBDU).

IBD diagnosis was based on the typical clinical course of the disease and endoscopic examination with histological confirmation of IBD. A diagnosis of IBDU was considered when the morphology included overlapping features of $\mathrm{UC}$ and $\mathrm{CD}$ regarded as inconsistent with either diagnosis. All information regarding disease was obtained in a prepared performa. The past records of patients were also used for retrieving information. The extent and severity of UC was classified as per Montreal. The patients of CD were classified on basis Montreal classification and severity assessed by Harvey Bradshaw index.

\section{Results}

During study period 101 patients of IBD presented to our hospital. UC was noted in $83(82 \%)$ patients followed by $\mathrm{CD}$ in $12(12 \%)$ patients and IBDU was noted in $6(6 \%)$ patients. Fifty eight $(57.42 \%)$ were old cases seen on follow up and 43 (42.58\%) were newly diagnosed.

The age ranged from 18-76 years with a mean age of $43.56 \pm 14.13$ years (UC- $43.87 \pm 13.67 \mathrm{yrs,} \mathrm{CD-}$ $43.5 \pm 15.93 \mathrm{yrs}$ and IBDU-36.5 $\pm 15.06 \mathrm{yrs})$ Forty three $(42 \%)$ were aged $<50$ yrs. Half of patients of CD and IBDU were aged $<50 \mathrm{yrs}$. The overall females to male ratio in study group were 1.02:1. The sex distribution was almost equal in UC however CD had more (66\%) males and IBDU group had more (66\%) female patients. Majority of patients were from rural background in all three groups. Thirty two (32\%) belonged to lower middle class, 28(28\%) upper lower and upper middle class and $12 \%$ belonged to upper class (Modified Kuppuswamy Scale).

As per BMI classification for Asians in UC group 39 (47\%) had normal BMI, 32(38\%) were underweight, 10 (12\%) were overweight. In CD group $9(75 \%)$ had normal BMI and in IBDU 2(33\%) patients were underweight, normal and overweight each.

The vegetarianism (UC-58\%, CD-75\%, IBDU$66.67 \%$ ), smoking (UC-23\%, CD-42\%), use of NSAIDs in preceding 3 months (UC-23\%, CD-17\%, IBDU$17 \%)$, consumption of alcohol (17\% in all groups), use of tobacco (UC-13\%, CD-8\%, IBDU-17\%) were main factors associated.

In UC patients, 66 (79\%) patients were diagnosed within one year of the onset of symptoms. In CD group, 9 (75\%) patients were diagnosed within 9 months of onset of symptoms. In IBDU group, 5 (83\%) patients were diagnosed with in one year of onset of symptoms.

Table 1 delineates different symptoms and their occurrence in types of IBD at presenting complaints. Intestinal obstruction was noted in $7(7 \%)$ patients, of total $3(4 \%)$ patients of UC (1 patient had dynamic 
Table 1: Symptoms at onset of inflammatory bowel disease

\begin{tabular}{l|l|l|l|l|l|l|l|l}
\multicolumn{1}{c|}{ Symptoms } & \multicolumn{2}{c|}{ Total } & \multicolumn{2}{c|}{ Ulcerative Colitis } & \multicolumn{2}{c|}{ Crohn's Disease } & \multicolumn{3}{c}{ IBDU } \\
\hline & $\mathbf{n = 1 0 1}$ & $\mathbf{\%}$ & $\mathbf{n = 8 3}$ & $\mathbf{8}$ & $\mathbf{n = 1 2}$ & $\mathbf{\%}$ & $\mathbf{n = 6}$ & $\%$ \\
Diarrhea & 94 & 93 & 81 & 97 & 8 & 67 & 5 & 83 \\
\hline Blood in stool & 92 & 91 & 78 & 94 & 9 & 75 & 5 & 83 \\
\hline Weight loss & 72 & 71 & 61 & 73 & 8 & 75 & 3 & 50 \\
\hline Mucus in stool & 88 & 87 & 75 & 90 & 8 & 67 & 5 & 83 \\
\hline Abdominal pain & 62 & 61 & 48 & 58 & 10 & 83 & 4 & 67 \\
\hline Tenesmus & 53 & 52 & 50 & 60 & 2 & 17 & 1 & 17 \\
\hline Urgency & 50 & 49 & 46 & 55 & 2 & 17 & 2 & 33 \\
\hline Fever & 17 & 17 & 14 & 17 & 1 & 8 & 2 & 33 \\
\hline Intestinal Obstruction & 7 & 7 & 3 & 4 & 4 & 33 & 0 & 0
\end{tabular}

obstruction and was subjected to extended hemicolectomy for subacute intestinal obstruction and 2 patients had adynamic (hypokalemia) obstruction), whereas 4 (33\%) patients of CD had dynamic intestinal obstruction and 1 of them was subjected to surgery for stricture in colon.

\section{Ulcerative Colitis}

In UC patients, the extent of disease was noted as per Montreal classification. E1 disease was seen in 23 (27.71\%), E2 in 38 (45.78\%) and E3 in 22 (26.5\%). The severity of UC at onset was also graded as per Montreal classification. S1 disease was seen in 8(9.63\%), S2 in 42 (50.60) and S3 in 33 (39.76\%). Of the 40 old UC patients with follow up of more than one year at least, 21 (42\%) had intermittent flares, 17 (34\%) had single episode and 12 (24\%) had chronic continuous disease. In UC, 70(84\%) achieved remission with ASA, 11 (13\%) needed ASA and steroids and $2(2 \%)$ patients needed ASA, steroids and azathioprine.

\section{Crohn's Disease}

The disease distribution of $\mathrm{CD}$ was classified as per Montreal classification is given in Table 2. As per Harvey Bradshaw Index, $67 \%$ had moderate disease, $17 \%$ had mild disease and remaining $17 \%$ patients were in remission. Of the 4 old patients of $\mathrm{CD}$ with follow up of more than one year at least, $2(50 \%)$ had single episode and 1 (25\%) each had intermittent flares and chronic continuous disease. In
Table 2: Disease classification of Crohn's Disease (Montreal Classification)

\begin{tabular}{c|c} 
Variable & $\mathbf{n = 1 2}(\%)$ \\
A1 (<16years) & not included in study \\
\hline A2 (Age 17-40years) & $7(58)$ \\
\hline A3 (Age >40years) & $5(42)$ \\
\hline L1 ( ileum) & $3(25)$ \\
\hline L2 (colon) & $6(50)$ \\
\hline L3 (ileocolic) & $3(25)$ \\
\hline $\begin{array}{c}\text { L4 (isolated upper disease } \\
\text { modifier) }\end{array}$ & $0(0)$ \\
\hline $\begin{array}{c}\text { B1 (non stricturing non } \\
\text { penetrating) }\end{array}$ & $8(67)$ \\
\hline B2 (stricturing) & $4(33)$ \\
\hline B3 (penetrating) & $0(0)$ \\
\hline Perianal disease modifier (p) & $0(0)$
\end{tabular}

CD, 11 (92\%) improved with ASA and 1(8\%) needed ASA, steroids and azathioprine.

\section{Inflammatory Bowel Disease Undifferentiated}

Left sided colon involvement was seen in $5(83 \%)$ patients and $1(17 \%)$ patient had right sided involvement in IBDU. Three (75\%) had single episode and 1 (25\%) had intermittent flares remaining 2 patients were newly diagnosed. None of the patients had fulminating disease. In all, $6(100 \%)$ patients of IBDU remission was achieved with ASA alone. 
Table 3 shows various extra-intestinal manifestations (EIMs) in the study group. At least one EIM was present in $43(42 \%)$ of the patients, 2 EIMs were present in $20(20 \%)$ and $\geq 3$ EIMs were present in 8 (8\%). In UC group, one patient had colorectal carcinoma and suffered from UC for 25 years and one patient had cholangiocarcinoma.

\section{Discussion}

The ratio of UC:CD was 1.82:1 in a study by Makharia et al. ${ }^{5}$ This ratio in this study was 6.9:1 in present study. The ratio though is higher than the survey in India but in sub analysis of survey this ratio of UC:CD was 2.05:1 for north zone and 8.1:1 in central zone of India. There were only $0.4 \%$ cases of IBDU in the survey, but in this study the proportion was higher with $5.9 \%$ which is in consistency with Chinese study by Zhou et al. ${ }^{1,5}$ In the present study $80 \%$ patients belonged to rural and $20 \%$ belonged to urban areas and could be since in Himachal Pradesh about $90 \%$ population resides in rural areas. In this study, maximum number of patients in UC were $(44.19 \%)$ in the age group 31-45 years as seen in study. The mean age of the patients was $43.52+/-13.67$, which was higher than $38.5+/-13.5$ seen in study by Makharia et al. ${ }^{5}$ The mean age of the patients of CD was $43.5+/$ 15.93 years with mean age of females was 44 years and 43.25 years for males. In another study by Das et al from the mean age of onset was $33.2+/-13.6$ years. ${ }^{6}$ The median age of patients of IBDU 29.5 years as compared to 40.22 years in study by Zhou $\mathrm{N}$ et al. ${ }^{1}$ The average BMI of IBD was $19.69 \mathrm{~kg} / \mathrm{m}^{2}$ in our study which was like $19.8 \mathrm{~kg} / \mathrm{m}^{2}$ seen in a study by Ghoshal et al. ${ }^{7}$ Most patients in this study were vegetarian however $93 \%$ patients of UC were non-vegetarian in a study conducted in South of India by Gunishetty et al. ${ }^{8}$ In UC patients, $23 \%$ were smoker compared to $14 \%$ in a study by Russel et al. In CD group $42 \%$ were smokers and in the study by Russel et al, $27 \%$ smoked. ${ }^{9}$ This shows consistency with association of smoking with decreased risk of UC and increased risk of CD. In another Indian study by Gunishetty et al 5\% of UC patients were smokers compared to $12 \%$ in controls. ${ }^{8}$

There were $23 \%$ patients of UC and $17 \%$ of CD with history of NSAIDS use in preceding 3 months, which was higher in UC (19\%) but lower in CD (30\%) as reported by Bernstein et al. ${ }^{10} \mathrm{~A}$ study by Ozin et al reported that $33 \%$ patients of $\mathrm{CD}$ were current NSAIDS users. ${ }^{11}$ In present study $16 \%$ patients of UC and $17 \%$ of CD had history of consumption of alcohol, comparable to Makharia et al, the history of consumption of alcohol was noted in $13 \%$ of patients of UC and in $12 \%$ patients of CD. ${ }^{5}$ Gunisetty et al reported alcohol use in $29 \%$ patients of UC. ${ }^{8}$ In this study, in $2 \%$ patients of UC and none in CD group had undergone appendicectomy. Russel et al reported that $5 \%$ patients of $\mathrm{UC}$ and $11 \%$ in $\mathrm{CD}$ group had history of appendectomy. ${ }^{9}$ Makharia et al reported

\section{Table 3: Extra-intestinal manifestations in inflammatory bowel diseases}

\begin{tabular}{l|l|l|l|l|l|l|l|l} 
Extra-intestinal & \multicolumn{3}{|c|}{ Total } & \multicolumn{3}{c|}{ Ulcerative Colitis } & \multicolumn{3}{c}{ Crohn's Disease } & \multicolumn{3}{c}{ IBDU } \\
\hline & $n=101$ & $\%$ & $n=83$ & $\%$ & $n=12$ & $\%$ & $n=6$ & $\%$ \\
\hline Peripheral Arthralgia & 35 & 35 & 26 & 31 & 6 & 50 & 3 & 50 \\
\hline Central Arthralgia & 22 & 22 & 19 & 23 & 2 & 17 & 1 & 17 \\
\hline Episcleritis & 14 & 14 & 10 & 12 & 2 & 17 & 2 & 33 \\
\hline Erythema nodosum & 6 & 6 & 4 & 5 & 1 & 8 & 1 & 17 \\
\hline Thromboembolism & 2 & 2 & 2 & 2 & 0 & 0 & 0 & 0 \\
\hline Reactive Arthritis & 2 & 2 & 0 & 0 & 1 & 8 & 1 & 17 \\
\hline Iritis & 2 & 2 & 1 & 1 & 1 & 8 & 0 & 0 \\
\hline Malignancy of colon & 1 & 1 & 1 & 1 & 0 & 0 & 0 & 0 \\
\hline Ankylosing Spondylitis & 1 & 1 & 1 & 1 & 0 & 0 & 0 & 0 \\
\hline Cholangiocarcinoma. & 1 & 1 & 1 & 1 & 0 & 0 & 0 & 0
\end{tabular}


a definite family history of IBD in one or more family members in $(3 \%)$ patients of IBD. ${ }^{5}$ In present study, none had family history of IBD. This difference could largely be because of unawareness of IBD in rural areas.

\section{Ulcerative Colitis}

The findings of present study in UC are in agreement with Makharia et al who observed blood in stool present in $86 \%$ patients, diarrhea in $82 \%$, mucus in $75 \%$, abdominal pain in $67 \%$, weight loss in $62 \%$ and fever in $22 \%$ patients. $^{5}$ The extent of disease in this study were similar to Sood et al reported that $47 \%$ patients presented with left sided colitis, $27 \%$ had pancolitis and $25 \%$ had proctosigmoiditis. ${ }^{12}$

In study by Makharia et al EIMs were present in $50.6 \%$ of UC patients, 1 EIM in 29.6\%, 2 EIMs in $17.7 \%$ and 3 EIMs in $3.2 \% .^{5}$ In the study by Bandyopadhyay et al at least one extra-intestinal manifestation was present in $40 \%$ patients of UC, Two extra-intestinal manifestation was present in $12 \%$ and $\geq 3$ were present in $7 \%$ patients. ${ }^{13}$ In the study by Singh B et al, EIMs were seen in 33.2\% of UC patients. ${ }^{17}$ Kochhar R et al reported EIMs in $34.7 \%$ patients of UC and musculoskeletal manifestations were most common followed by ocular manifestations (8\%). ${ }^{18}$ In the present study $40 \%$ of UC patients had at least 1 EIM, 13\% had 1 EIM, 16\% had 2 EIMs and 11\% $\operatorname{had} \geq 3$ EIMs. Most common EIM was in musculoskel et al symptoms as arthralgia peripheral in $31 \%$ and central in $23 \%$. In the study by Bandyopadhyay et al arthritis was present in $21 \%$ patients, ankylosing spondylitis in $16 \%$, episcleritis in $14 \%$ and mucocutaneous lesions in $12 \%$ patients. ${ }^{13}$ Makharia et al observed arthralgia in 33\% patients, backache in $31 \%$ and skin lesion in $2 \%$ patients. ${ }^{5}$

Of the total 58 patients with follow up of at least 1 year $22(37.9 \%)$ had single episode and were in remission, 23 (39.7\%) number had intermittent flares and $13(22.4 \%)$ patients had chronic continuous disease. Of 50 old UC patients $42 \%$ had intermittent flares, $34 \%$ had single episode and $24 \%$ had chronic continuous disease. In the study by Makharia et al $47 \%$ patients had intermittent flares, $35 \%$ had chronic continuous disease and $17.2 \%$ had single episode. ${ }^{5}$

\section{Crohn's Disease}

In the present study, the patients with $C D$ disease had similar presentation with pain abdomen, weight loss and

Table 4: Comparison of the present study with survey of inflammatory bowel disease in India

\begin{tabular}{l|c|c|c|c}
\hline \multirow{2}{*}{ Variable } & \multicolumn{2}{|c|}{ Ulcerative colitis } & \multicolumn{2}{c}{ Crohn's disease } \\
\hline Mean Age(SD) & Present study & ISG Survey & Present study & ISG Survey \\
\hline Male:Female & $43.8(13.67)$ & $38.5(13.5)$ & $43.5(15.9)$ & $35.9(13.9)$ \\
\hline Diarrhea & 0.93 & 1.4 & 2 & 1.3 \\
\hline Blood in stool & 97 & 82.2 & 67 & 64.6 \\
\hline Weight loss & 94 & 86.4 & 75 & 42.2 \\
\hline Mucus in stool & 73 & 61.9 & 75 & 66.1 \\
\hline Abdominal pain & 90 & 75.5 & 67 & 37.4 \\
\hline Fever & 58 & 66.7 & 83 & 74.9 \\
\hline No EIM & 17 & 25.6 & 8 & 42.9 \\
\hline Single EIM & 60 & 49 & 50 & 43.1 \\
\hline Two EIMs & 13 & 30 & 17 & 34.9 \\
\hline Three or more EIMs & 16 & 18 & 25 & 18.5 \\
\hline Single episode & 11 & 3 & 8 & 3.6 \\
\hline Intermittent flare & 38 & 17 & 50 & 8.1 \\
\hline Chronic continuous disease & 40 & 36 & 25 & 23.1 \\
\hline
\end{tabular}


chronic diarrhea being common symptoms as reported by Makharia et al. ${ }^{5}$ Another study by Ghoshal et al reported bloody diarrhea in $68 \%$ patients, abdominal pain in $62 \%$, weight loss in $57 \%$ and intestinal obstruction in $28 \%$ patients. $^{7}$ In study by Santana et al, with respect to age at diagnosis, $70 \%$ were classified as $\mathrm{A} 1$ and $30 \%$ as $\mathrm{A} 2$ as per Vienna classification. In this study as per Montreal classification 58\% patient were from 17-40 years of age. $50 \%$ had L 2 disease and $67 \%$ had B 1 disease. In that study as per Vienne classification $19.1 \%$ had L1, 21\% were classified as L2, $38 \%$ as L3 and $21 \%$ as L4. According to the disease behavior, $47 \%$ were classified as B3, $13 \%$ as B2 and $40 \%$ as B1 14 .

The severity of $\mathrm{CD}$ at the time of initial presentation was assessed as per Harvey Bradshaw Index. In present $67 \%$ had moderate disease and $17 \%$ were in remission and mid disease each compared to study by Plevy et al, 66\% were in remission, $17 \%$ had mild disease and $16 \%$ had moderate/severe disease. ${ }^{15}$

It was observed in study by Bandyopadhyay et al, 24\% patients had arthritis, 19\% had ankylosing spondylitis, $13 \%$ had ocular manifestations and mucocutaneous lesion in $7 \%$ patients. ${ }^{13}$ In study by Makharia et al backache was seen in 36\% patients, arthralgias in $26 \%$ and $3 \%$ patients had skin lesions, similarly in this study $50 \%$ of CD patients had EIMs and arthralgias were seen most commonly. ${ }^{5}$ In study by Singh B et al EIMs were seen in $38.3 \%$ of CD patients, peripheral arthropathy and erythema nodosum were more common in CD then in UC. ${ }^{17}$ Of the 4 old patients of CD $50 \%$ had single episode and $25 \%$ each had intermittent flares and chronic continuous disease. Makharia et al observed that $69 \%$ patients of CD had intermittent flares, $23 \%$ had chronic continuous disease and $8.1 \%$ had single episode. $^{5}$

\section{Inflammatory Bowel Disease Undifferentiated}

In the present study patients of IBDU presented with diarrhea, blood in stool and mucus in stool in $83 \%$ patients each, abdominal pain in $67 \%$, weight loss in $50 \%$. In a study by Zhou $\mathrm{N}$ et al and Bermejo et al also had abdominal pain the most common symptom was abdominal pain, diarrhea, weight loss and fever as most common presenting features in IBDU..$^{1,16}$
In this study, left sided colon involvement was seen in $5(83 \%)$ patient and $1(17 \%)$ patient had terminal ileum involvement. In a study of the 27 patients by Zhou et al, $11 \%$ had pancolonic involvement, $15 \%$ had primarily left sided and right sided involvement respectively, 52\% had small bowel involvement and 7\% had extensive involvement. ${ }^{1}$ In study by Bermejo et al, $46 \%$ had extensive colitis, $29 \%$ had distal colitis, $8 \%$ had colitis with rectal sparing and $17 \%$ had variable location. ${ }^{16}$ Extra-intestinal manifestations were present in $67 \%$ patients in the present study. One and two extra-intestinal manifestations were present in 33\% patients each. Zhou et al et al reported arthralgia, erythema nodosum and mucocutaneous abscess in $11 \% .{ }^{1}$ In total $74(73 \%)$ patients had anemia at presentation, $64(77 \%)$ patients of UC, $6(50 \%)$ patients of $\mathrm{CD}$ and $4(67 \%)$ patients with IBDU had anemia. This paper highlights the similarities and differences of demographics and clinical characteristics of IBD patients in this region of India compared to other studies from different region of India and Asia. The limitation of this study included limited number of CD and IBDU patients and short study period.

In conclusion IBD is not uncommon in western Himalayas and rural areas. UC is the most common IBD seen. In every patient presenting with chronic diarrhea, chronic pain abdomen, blood in stools, weight loss, anemia and hypoalbuminemia, it should be a strong differential.

\section{References}

1. Zhou N, Chen W, Chen S, Xu C, Li Y. Inflammatory bowel disease unclassified. $J$ Zhejiang Univ-Sci B (Biomed \& Biotechnol). 2011;12(4): 280-6.

2. Yang SK, Loftus EV Jr., Sandborn WJ. Epidemiology of inflammatory bowel disease in Asia. Inflamm Bowel Dis. 2001;7(3):260-70.

3. Froklis A, Dieleman LA, Barkema HW, Panaccione R, Ghosh S, Fedorak RN et al. Environment and the Inflammatory Bowel Diseases. Can $J$ Gastroenterol. 2013;27(3): 18-21.

4. Bernstein CN, Fried M, Krabshuis JH, Cohen H, Eliakim R, Fedail S et al. Inflammatory Bowel Disease: A Global Perspective. WGO Global Guidelines. 2009.

5. Makharia GK, Ramakrishna BS, Abraham P, Choudhuri G, 
Misra SP, Ahuja V et al. Survey of inflammatory bowel diseases in India. Indian J Gastroenterol. 2012;31(6): 299306.

6. Das K, Ghoshal UC, Dhali GK, Benjamin J, Ahuja V ,Makharia GK. Crohn's disease in India: a multicenter study from a country where tuberculosis is endemic. Dig Dis Sci. 2008;54: 469.

7. Ghoshal UC, Shukla A. Malnutrition in inflammatory bowel disease patients in northern India: frequency and factors influencing its development. Tropical Gastroenterol. 2008;29(2): 95-7.

8. Gunisetty S, Tiwari SK, Bardia A, Phanibhushan M, Satti $\mathrm{V}$, Habeeb MA et al. The epidemiology and prevalence of Ulcerative colitis in the South of India. Open J Immunology. 2012; 2(4):144-8.

9. Russel MG, Dorant E, Brummer RJM, Kruus MAV, Muris $\mathrm{JW}$, Bergers JM et al. Appendectomy and the risk of developing ulcerative colitis or crohn's disease: results of a large case-control study. Gastroenterol. 1997;113:377-82.

10. Bernstein CN, Rawsthorne P, Cheang M. A populationbased case control study of potential risk factors for IBD. Am J Gastroenterol. 2006;101:993-1002.

11. Ozin Y, Kilic MZY, Nadir I, Cakal B, Disibeyaz S, Arhan $\mathrm{M}$ et al. Clinical features of ulcerative colitis and crohn's disease in Turkey. J Gastrointestin Liver Dis. 2009;18(2): $157-62$.

12. Sood A, Midha V, Sood N, Puri S, Kaushal V. Profile of ulcerative colitis in a north Indian hospital. Journal of Indian Academy of Clinical Medicine. 2000;5(2):124-8.
13. Bandyopadhyaya D, Bandhyopadhyay S, Ghosh P, De A, Bhattacharya A, Dhali GK et al. Extraintestinal manifestations in inflammatory bowel disease: prevalence and predictors in Indian patients. Indian J Gastroenterol. 2015;34(5):387-94.

14. Santana GO, Souza LR, Azevedo M, Carolina A, Bastos CM, Lyra C. Application of Vienna Classification for crohn's disease to a single centre from Brazil. Arq Gastroenterol. 2008;45(1):64-8.

15. Plevy S, Silverberg MS, Lockton S, Stockfisch T, Croner $\mathrm{L}$, Stachelski J et al. Combined serological, genetic, and inflammatory markers differentiate non-IBD, crohn's disease, and ulcerative colitis Patients. Inflamm Bowel Dis. 2013;19(6):1139-48.

16. Bermejo F, Algaba A, Cuno JL, Botella B, Taxonera C Lopez-Serrano $\mathrm{P}$ et al. Inflammatory bowel disease unclassified(IBDU) in real practice: prevalence, clinical course and therapy requirements. European Crohn's and Colitis Organisation. Poster presentation: Clinical: Diagnosis and outcome. 2013:P216.

17. Singh B, Kedia S, Konijeti G, Mouli VP, Dhingra R, Kurrey $\mathrm{L}$ et al. Extraintestinal manifestations of inflammatory bowel disease and intestinal tuberculosis: Frequency and relation with disease phenotype. Indian J Gastroenterol. 2015;34(1):43-50.

18. Kochhar R, Mehta SK, Nagi B, Bhatia V, Goenka MK, Malik AK. Extraintestinal Manifestations of Idiopathic Ulcerative Colitis. Indian J Gastroenterol. 1991; Vol 10(3):88-89. 